\title{
Rural Masculinities and the Internalisation of Violence in Agricultural Communities ${ }^{1}$
}

Kerry Carrington, Head

School of Justice, Queensland University of Technology

Gardens Point Campus, GPO Box 2434

Brisbane, Queensland, 4001

Australia

Alison McIntosh, Senior Research Associate

School of Justice, Queensland University of Technology

Gardens Point Campus, GPO Box 2434

Brisbane, Queensland, 4001

Australia

Russell Hogg, Professor

School of Justice, Queensland University of Technology

Gardens Point Campus, GPO Box 2434

Brisbane, Queensland, 4001

Australia

John Scott, Professor

School of Behavioural, Cognitive and Social Science

University of New England

Armidale, New South Wales, 2350

Australia

Contact author - Kerry Carrington: kerry.carrington@qut.edu.au; +61 0731387112

\begin{abstract}
This article is based on research we conducted in two agricultural communities as part of a broader study that included mining communities in rural Australia. The data from the agricultural locations tell a different story to that of the mining communities. In the latter, alcohol-fuelled, male-on-male assaults in public places caused considerable anxiety among informants. By contrast, people in the agricultural communities seemed more troubled by hidden violent harms which were largely privatised and individualised, including self-harm, suicide, isolation and threats to men's general wellbeing and mental health; domestic violence; and other forms of violence largely unreported and thus unacknowledged within the wider community (including sexual assault and bullying linked to homophobia). We argue one reason for the different pattern in the agricultural communities is the decline of pub(lic) masculinity, and with this, the increasing isolation of rural men and the increasing propensity to internalise violence. We argue that the relatively high rates of suicide in agricultural communities experiencing rural decline are symptomatic of the internalisation of violence.
\end{abstract}

Keywords: Rural Men, Agriculture, Self Harm, Domestic Violence, Drinking Culture 
Rural Maculinities and the Internalisation of Violence in Agricultural Communities Carrington, McIntosh, Hogg \& Scott

\section{Introduction}

This paper draws upon original research undertaken for an Australian Research Council Discovery project on masculinity and violence in rural settings. Our research team set out to explore why (non-Indigenous) men living in regional and remote areas of Australia experience higher mortality and morbidity rates related to violence than men living in the nation's major cities (Carrington, McIntosh \& Scott, 2010; Carrington \& Scott, 2008). We used a mixed methods approach triangulating secondary quantitative data with primary qualitative data. Importantly our methodology was not explicitly aimed at contrasting the patterns of violence that eventually became apparent between agriculture and mining communities, which emerged from the data itself. In this article, the primary focus is on the agricultural communities, with selected comparisons to our findings in the mining communities.

\section{Project and Method}

We used a mixed methods approach, triangulating quantitative measures of violence (such as violent related crimes and injuries; deaths and illnesses caused by violence, motor vehicle accidents; risky alcohol consumption; firearm injuries; domestic violence orders and injury surveillance data) with qualitative field research. The team performed wide-ranging analyses of existing databases for socio-demographics, crime, mortality, morbidity, injury and accident data across more than 40 Local Government Areas (LGAs) within rural New South Wales (NSW), Queensland (Qld) and Western Australia (WA), generating 12 data reports which are available on QUT ePrints. In the Australian system, LGAs are the third and lowest tier of government and those with lower population densities are usually larger in geographic size. The norm is for LGAs to have one identifiable service (market) town, which is the centre of governance for the provision of local roads, a limited range of community services and facilities, and town planning and development (but not of mines and associated infrastructure which are mostly approved at state government level, sometimes with federal approval also required), plus a hinterland interspersed with numerous smaller towns and villages and, of particular interest for this article, many agricultural holdings (farms, properties or ranches) of varying sizes within identifiable rural localities. From these analyses, three LGAs with measures indicating high rates of violence were selected for fieldwork. Each selected LGA contained a number of identifiable communities and all had resident populations at the time of the 2006 Census of around 16,000 persons.

Over a two year period we conducted field research in these communities, interviewing a purposive sample of 142 civic leaders, community representatives, justice officials, and human and medical service providers across both mining and agricultural communities. Given the sensitive nature of research on violence, gender, men's health and community safety and wellbeing in small rural villages and towns, protecting the anonymity of respondents was an over-riding ethics requirement. The communities involved in the study were often characterised by limited, but visible, service provision, making it possible to identify individuals according to roles. Hence, pseudonyms have been used to refer to both the region and towns involved in the study.

A semi-structured interview schedule was used to explore rural men's health, wellbeing, and patterns of violence. At the end of interviews, participants completed a basic survey which allowed 
overall demographic characteristics to be assessed. All interviews were recorded with permission. The interview data were coded and transcribed according to emerging themes (Spradley, 1979) until a 'codebook' evolved (Miles \& Huberman, 1994). Violence "turned inward" and violence "turned outward" emerged as two key themes from the analysis of the qualitative data.

Rurality is a contested concept defined differently among the social science disciplines (Hogg $\&$ Carrington, 2006). Our concept of a rural community recognizes it is not static, ahistorical or placeless and seeks to investigate the interaction between sociality and spatiality - what we have previously theorised as the architecture of rural life (Hogg \& Carrington, 2006). Our case studies explored how the social characteristics of that architecture - masculinities associated with rural occupations of farming and mining; challenges to the gendered rural social order; the globalisation of agricultural and mining industries; the imaginary boundaries of rurality which define who belongs and who does not; deeply held rural ideologies about resilience and self-reliance influence the patterns of cultural conflict and violence. While case study methodologies have limited generalizability, our study has sought to triangulate these characteristics with national data where possible to enhance both reliability and external validity.

\section{The Settings: Standon, NSW and Baredge, Queensland}

Categorised by the ABS remoteness structure ${ }^{2}$ as 'Outer Regional', Standon has a comparatively long history (over 150 years) of white settlement primarily dependent upon relatively prosperous agricultural activities including irrigated and dryland broadacre cropping, and sheep, wool and beef cattle production. The Standon LGA experienced only modest population growth, less than 5\%, over the two inter-censual periods from 1997 to 2006 (Infrastructure, 2008). Over $60 \%$ of Standon's population lives in the main town of 'Corundula', the service centre for the LGA. The remainder live in small towns, villages and rural localities.

Recent research by Vinson $(1999,2004,2007)$ measured social disadvantage and social exclusion in Australian communities. ${ }^{3}$ Local areas are ranked from 1-5 according to level of disadvantage where 1 represents the least disadvantaged communities. Standon scored a ranking of 5 (Vinson, 2007), indicating serious disadvantage. Moreover, the Standon LGA was assessed as having the highest ranking of 4 (on a NSW statistical scale) for domestic violence-related criminal assault. These quantitative measurements point to Standon exhibiting attributes associated with vulnerable communities (Baum et al., 1999; Baum \& Stimson, 2005).

Our other agricultural case study is a district we call Baredge, in the Brahmley LGA, hundreds of kilometres from the Queensland state capital of Brisbane. From the time of European settlement in the mid-1800s, this region has been renowned for beef production as well as dryland and irrigation cropping. The LGA has experienced only modest growth from 2005 to 2010, in the range $0-0.5 \%$, well below the average for the State, which is around $2.5 \%$ (ABS, 2011).

About half the LGA's population live on rural holdings and in the small towns and villages in the Baredge district, with the remainder in Serveton. Severton is that part of the LGA which includes the main service town and a nearby mining town. Agricultural production remains important for Baredge although recently its dominance has waned in part due to prolonged drought. 
Rural Maculinities and the Internalisation of Violence in Agricultural Communities -

Carrington, McIntosh, Hogg \& Scott

Table1: Selected Characteristics for All Males by Study Location (percent)

\begin{tabular}{lccc}
\hline Characteristics & $\begin{array}{c}\text { Standon } \\
\text { NSW }\end{array}$ & $\begin{array}{c}\text { Baredge } \\
\text { Qld }\end{array}$ & Australia \\
\hline Proportion of total population - male & 49.3 & 51.8 & 49.4 \\
Identified as Indigenous & 5.2 & 2.6 & 2.3 \\
Born in Australia & 90.4 & 90.1 & 70.7 \\
Aged 0-14 years & 23.1 & 23.2 & 20.6 \\
Aged 15-24 years & 11.3 & 10.4 & 14.1 \\
Aged 25-44 years & 22.9 & 25.9 & 28.1 \\
Aged 45-64 years & 26.5 & 27.8 & 25.1 \\
Aged 65 years and over & 16.1 & 12.7 & 12.1 \\
\hline Currently married or in de facto relationship & 46.7 & 49.3 & 46.5 \\
Living in lone person households & 5.1 & 10.5 & 9.0 \\
Living in private dwelling & 95.7 & 86.1 & 96.6 \\
Participating in voluntary work & 22.1 & 26.0 & 15.7 \\
\hline Lived at same address: & & & \\
1 year ago & 79.9 & 80.3 & 78.3 \\
Not stated & 4.0 & 5.2 & 5.9 \\
Lived at same address: & & & 52.9 \\
$\quad$ 5 years ago & 54.0 & 59.6 & 7.0 \\
\hline Not stated & 5.0 & 5.9 & \\
\hline
\end{tabular}

Source: ABS (2008) 2006 Census of Population and Housing

Thus it might be expected that Baredge has experienced negative impacts in common with Standon in NSW. Nevertheless, Baredge is apparently not as disadvantaged as Standon, with a mid-point ranking of 3 on Vinson's (2007) scale. Importantly, the mining industry in adjacent Serveton has provided well-paid job opportunities.

Regional and remote areas have historically tended to be more homogeneous with respect to ethnicity of residents than metropolitan cities (Hogg \& Carrington, 2006). In both locations, few residents were born overseas (less than 10\%) and even fewer identified as Indigenous (Table 1). Low proportions had non-school qualifications compared to the Australian average (Table 2). Unemployment rates were comparatively low in Baredge, but high in Standon. Both localities had considerably fewer professionals and service personnel and more labourers, trade workers and managers than Australian averages.

In summary, both areas appear relatively disadvantaged with respect to human capital and services, with Standon more so than Baredge. Conversely, levels of volunteering suggest higher social capital than for Australia overall.

\section{Frontier Masculinities and Patterns of Violence in Agriculture Versus Mining Communities}

We have previously published some results of our analysis of frontier masculinities and violence in Australian mining communities (see Carrington et al., 2010; Carrington et al., 2011; Carrington \& Hogg, 2011; Scott et al., 2012). In those mining communities undergoing 
Table 2: Selected Characteristics for Adult Males by Agricultural Study Location (percent)

\begin{tabular}{|c|c|c|c|}
\hline Characteristics & $\begin{array}{c}\text { Standon } \\
N S W\end{array}$ & $\begin{array}{c}\text { Baredge } \\
\text { Qld }\end{array}$ & Australia \\
\hline Adults in population & 76.8 & 77.0 & 79.4 \\
\hline Adults with a non-school qualification & 34.5 & 27.3 & 44.0 \\
\hline Certificate level non school qualification & 73.2 & 73.9 & 52.5 \\
\hline Adults unemployed & 8.2 & 1.4 & 5.2 \\
\hline Adults in the labour force & 62.7 & 78.4 & 66.6 \\
\hline Adults employed to population & 57.6 & 77.1 & 63.1 \\
\hline \multicolumn{4}{|l|}{ Adults employed in: } \\
\hline Agriculture, fishing \& forestry & 20.1 & 42.7 & 4.0 \\
\hline Mining & 0.9 & 13.1 & 1.8 \\
\hline Manufacturing & 14.7 & 6.1 & 14.4 \\
\hline Utilities & 1.9 & 2.6 & 1.4 \\
\hline Construction & 11.6 & 8.0 & 12.5 \\
\hline Wholesale trade & 3.8 & 3.1 & 5.3 \\
\hline Retail trade & 10.4 & 2.9 & 9.0 \\
\hline Accommodation \& food services & 3.6 & 1.9 & 5.0 \\
\hline Public admin \& safety & 6.6 & 5.5 & 7.0 \\
\hline Education \& training & 3.6 & 1.5 & 4.3 \\
\hline Health care/ social assistance & 4.6 & 1.0 & 4.2 \\
\hline Other & 15.9 & 9.3 & 28.3 \\
\hline \multicolumn{4}{|l|}{ Occupation: } \\
\hline Managers & 24.2 & 38.3 & 16.1 \\
\hline Professionals & 8.9 & 3.1 & 17.3 \\
\hline Technicians/trades workers & 20.8 & 15.1 & 22.7 \\
\hline Machinery operators/drivers & 10.0 & 20.1 & 11.0 \\
\hline Labourers & 19.8 & 16.1 & 12.3 \\
\hline Other & 16.3 & 7.3 & 20.6 \\
\hline \multicolumn{4}{|l|}{ Attending an educational institution: } \\
\hline $15-19$ years & 59.8 & 43.8 & 66.0 \\
\hline $20-24$ years & 15.7 & 4.1 & 29.5 \\
\hline \multicolumn{4}{|l|}{ With income: } \\
\hline less than $\$ 250$ per week & 30.4 & 19.4 & 24.6 \\
\hline$\$ 1,000$ or more per week & 11.0 & 27.1 & 25.1 \\
\hline$\$ 2,000$ or more per week & 1.6 & 7.8 & 5.6 \\
\hline
\end{tabular}

Note: 'Adult' refers to a male aged 15 years or over

Source: ABS 2006 Census of Population and Housing

rapid socio-demographic redefinition due to the influx of thousands of fly-in, fly-out (FIFO) and / or drive-in, drive-out (DIDO) workers, ${ }^{4}$ pub(lic) masculinity was on the rise. Pub(lic) masculinity refers to the way pub culture exerts a significant normalising influence over young men who become incorporated into a localised culture of masculinity through their participation in drinking rituals (Campbell, 2000: 563; Campbell, 2006). The rise in pub(lic) masculinity in mining communities has consequences for the patterning of frontier cultural conflict, where non-resident workers have become emblematic of the destruction of communal solidarities caused by postindustrial mining regimes and mobile workforce practices. The number of liquor licences and outlets were increasing, as were the customers, skimpy bar maids, pole dancers and FIFO / DIDO sex-workers. Sleepy country pubs had underdone radical transformation. Customer trade could hardly be better with the regular operation of courtesy buses to transport hundreds of NRWs from camps to pubs on a daily basis to coincide with the end of shift. These pubs had become venues for the negotiation of frontier rival masculinities where brawling and alcohol related violence was an everyday occurrence according to our participants, including the chief of police, magistrate, and health, emergency and medical service providers (Carrington et al., 2010). 
Rural Maculinities and the Internalisation of Violence in Agricultural Communities -

Carrington, McIntosh, Hogg \& Scott

The data collected in our agricultural study locations tell a different story. Instead of alcoholfuelled male-on-male assaults in public places causing most anxiety, participants in Standon and Baredge seemed more troubled by violent harms which were largely privatised, individualised and hidden from public view. These included self-harm, suicide, isolation and threats to men's general wellbeing and mental health; and other forms of violence largely unreported and thus often unacknowledged within the wider community, including domestic violence, sexual assault and violence, and bullying linked to homophobia.

One of the reasons, we believe, for the internalisation of violence in our agricultural communities is attributed to the decline of pub(lic) masculinity, the increasing privatisation of drinking and, with this, the increasing isolation of rural men (and women). This might account in part for statistically higher rates of domestic violence, suicide, and injury in parts of rural Australia. That our fieldwork in Standon and Baredge was conducted during a prolonged and extreme drought possibly served to accentuate previously existing conditions. But just because a drought breaks does not necessarily mean that these harms vanish. They simply remain hidden. For these reasons, we have chosen to direct our attention in this article towards hidden violence in private places identified by our research in agricultural communities.

\section{Hidden Violence within Private Places}

The unreported, hidden nature of domestic and sexual violence was a prominent thread recurring in our interviews with the service providers and professionals who dealt first hand with the victims of domestic and sexual violence in Baredge and Standon. The extent of domestic violence third-party reporting is unpredictable, as one police officer from a small rural town observed:

Sometimes they'll call police at the drop of a hat, sometimes they'll call if there's a dog barking; some other places won't call us when there's a violent domestic happening. There's people screaming and glass being broken, sometimes we can't understand how people haven't called us.

The social ordering of the private and public spaces of small townships insulates families from visibility, drawing a veil of privacy over any violence that might occur within it (Hogg \& Carrington, 2006). Domestic and family violence is more often concealed in rural areas or, as Alston (1997) pointed out, is easier to hide until visible signs on the victim of physical abuse have faded. Moreover, isolation from family and friends - especially for people living on rural properties but also for those new to an area - can mean that levels of support are not available for victims. Geographic isolation and lack of appropriate domestic violence support services also make reporting more difficult in rural contexts (Owen, 2012). Moreover, domestic violence victims from rural locations are often placed in 'away' refuges, removed from personal support networks. Otherwise the 'localising' of victims and perpetrators can lead to additional confrontation or fear of threatening behaviour. These contexts make exiting from violent relationships potentially quite dangerous (DeKeseredy \& Schwartz, 2009).

When police are called to domestic violence incidents in out-of-town localities, travel distances can translate into slow response times. Recognition of the likelihood of a delayed 
response enhances the risks of violent situations escalating before help arrives, influencing reporting decisions. For reported incidents, we were told the type and swiftness of police response often depends on previous experiences with the persons involved. As one experienced domestic violence liaison officer with the police commented:

Very rarely do we have to travel out of town for domestics and I would be assuming that's just because they would know how long it takes for the police to get there ... so they wouldn't be reporting.

Women living on farms were evidently less likely than town residents to seek support or even to appreciate that verbal and psychological abuse and harassment constituted domestic violence. One women's refuge manager believed they saw only 'the tip of the iceberg' with respect to abused out-of-towners:

Farmers' wives stay and put up with [domestic violence]; hope something's going to happen; because the partner's dependent on the wife to do half the work, feed the animals.

Support workers we interviewed told us that isolated victims were sometimes denied telephones or transport when partners were absent and access to money when visiting town was strictly controlled. Shame and a culture of keeping 'difficulties' secret were deterrents for seeking help. These problems became more evident under seasonal or financial pressures. A community health worker recounted this conversation with two out-of-town women who:

... came up and said: 'I wish I could come and talk to you'; and I said: Oh yes, we could go here or there. But the husbands had forbidden them, and that was the words they used, forbidden them; and that's a form of violence.

Our respondents - including police officers, service providers and victim support workers generally believed most out-of-town violence, especially domestic violence, remains unreported. Underreporting was also linked to lack of appropriate services in rural towns to effectively deal with situations. In reality, there is no way of knowing what's going on within families living outside the town. Expectations and concerns that 'eruptions' regularly occurred in some families would only come to light when someone with injuries came to the hospital for medical assistance.

On the one hand, lack of anonymity in rural areas added to social self-censorship. On the other hand, police officers and social service workers linked the likelihood of incident reporting to the establishment of trustworthy relationships. One policeman reflected:

Building that trust ... people are now ringing up and reporting incidents of ... even domestic violence whereas, whereas often in rural settings, that's not highly reportable because they're so isolated; there's only mum and dad on the property and there's no one else around them.

According to interviewed participants from the judicial system, rates of underreporting are most likely higher now than prior to mandatory reporting of domestic and sexual assault. Fear of 


\section{Rural Maculinities and the Internalisation of Violence in Agricultural Communities - \\ Carrington, McIntosh, Hogg \& Scott}

consequences if their partner / perpetrator is prosecuted can paralyse victims into inaction or turn them into hostile witnesses.

One counsellor we interviewed believed many people continue to think: 'It's the woman's fault because he was drunk and she made him angry'; while others think they shouldn't interfere or meddle in the private sphere. The reluctance to report is strongly related to dependency factors: financial dependency, the fear of relationship breakups, and the impacts on children. One victim support worker argued that domestic violence went largely unrecognized by victims, recalling:

I've had women say, you know, he doesn't hit me but then proceed to tell me two minutes later how he kicked her in the back, came flying across the [room], but that wasn't hitting. It's just amazing how women describe abuse is not abuse.

Based on numerous overheard bar conversations, a hotelier thought that the lifestyle of physically hard work and isolation of some farmers provided a different benchmark for acceptable behaviour:

I might hear: 'Such and such did this' and: 'The old man was the same'; you know, that sort of thing ... Being isolated, they don't see anything else, they just see that ... They grow up thinking that is normal.

Some also thought that social tolerance towards domestic violence was gradually diminishing. One prominent businessman provided an example of changing attitudes at his local pub:

There was a guy that was in the pub saying: 'She deserved what I gave her, a good smack in the ear.' And a really big bloke puts his arm around his shoulder and said to him: 'We don't do that here and we definitely don't skite about it in the pub. So I think you should go home and say you're sorry'.

We were repeatedly told that most were in denial about domestic violence in their community. For example, in small-population rural towns where anonymity is difficult, church charity groups often preferred to keep knowledge of domestic and family violence 'in house'; that is, secret and unrecorded even within their own systems. A Christian charity worker we interviewed in Standon recounted how known or suspected victims of family violence were supported by discretely organised visitations of medical, counselling and other emotional supports. He recounted:

She [religious sister of charity] takes around what she calls 'pamper packs' for the ladies and she reckons it's a boost to their ego or, and a consolation to them. And we go and visit them and if they're in financial strife we assist them with food and clothing and things like that ... We have a bit of a yarn to [the men] and just say: Would you like to have a yarn to us? ... [some say]: No; get lost; no; phssstt; keep your mind out of it; buzz off! ... Some of them say: Well, I don't know where to head; I've got myself into a bit of a corner and I don't know how to get out... 
These discrete practices are essentially aimed at maintaining the anonymity of perpetrators like the old boys' network that DeKeseredy (2011) describes as operating in North American rural communities. Habitual offenders are not referred to professionals and patterns of violence continue in some instances for generations.. This would make Standon a dangerous place for many rural women given its very high ranking for recorded domestic violence incidents in the State.

As with many forms of domestic and family violence, informants repeatedly told us that sexual assault was rarely reported because of, for instance, the processes required to get a conviction. Incest, especially between fathers and daughters, was nominated by some Braedge respondents as particularly problematic. Some believed the matter was openly discussed within their broader community while others described the subject as taboo.

Homophobic violence is another form of hidden violence in rural communities. Metropolitan and regional cities openly have gay communities. Rural Australia tends to be less diverse and tolerant of sexual difference with greater likelihood of overt and conspicuous discrimination. Moreover rural men have a limited range of acceptable masculinities which emphasise heteronormativity and physicality (Carrington \& Scott, 2008). As a church charity worker remarked:

We've vested as a country more into a sport hero or a muscular 'this is what the man's role is'; where, heaven forbid, if a man wants to become a hairdresser: he's called a poof.

Tolerance of difference obviously varies between locations. Our New South Wales study location had a reputation for homophobic violence, referred to by some professionals we interviewed as 'the underbelly of Standon'. Brahmley, our Queensland study location, also did not openly welcome homosexuals in their community. In fact, isolation was so complete that one support worker knew of gay men who did not know any other gay men in their own community, as disclosure was too risky. Perhaps for this reason, we could not locate gay men who were prepared to participate in confidential interviews. We were even told that male homosexuals essentially did not exist in farming communities; only in cities.

While recognizing that traditionally conservative values were progressively being challenged, 'old fashioned' attitudes can be more conspicuous in small rural communities where minorities are not easily concealed. A common view expressed among our rural informants was that gay males were more likely to suffer psychological abuse and bullying than physical violence. Problems are aggravated in rural areas by limited services and facilities. This means that it is unusual to find local refuges for victims of domestic violence within male homosexual relationships. Instead, help and support has to be sourced from geographically remote but larger centres, or not at all. Where there is little support or understanding for young men of sexually diverse orientation, the risk of suicide is greater (AIHW, 2010).

Although much of the domestic and sexual violence is also hidden in metropolitan areas, the architecture of rural life heightens the invisibility of interpersonal violence in rural contexts. A number of reasons have been suggested for this in the small but growing body of research on the topic. The intimacy and density of social-spatial relationships that characterise small rural 
Rural Maculinities and the Internalisation of Violence in Agricultural Communities -

Carrington, McIntosh, Hogg \& Scott

townships (Weisheit, Falcone \& Wells, 1996: 3) makes it more difficult for victims of violence to report it, seek outside help, or pursue protection through apprehended violence orders (Hogg \& Carrington, 2006). Social ties which are often strong within relatively homogenous rural communities can also influence under-reporting of violent crimes (Hogg \& Carrington, 2006). Influential families sometimes exert substantial pressure so that victims do not proceed with official complaints of sexual assault or applications for apprehended violence orders. Lack of anonymity enhances the sense of shame and embarrassment and acts as a deterrent to reporting (Alston, 1997). Moreover, informal social controls that operate through gossip networks have a powerful sanctioning effect in small rural communities (Macklin, 1995: 71). Additionally, strongly held rural ideologies of self-reliance operate as a form of self-censorship to deter victims from seeking outside help. Even if victims do report, an 'old boys' network' of informal social control protects perpetrators (DeKeseredy, 2011: 86). In sum, the architecture of rural life works to effectively hide 'private troubles' such as family, sexual, domestic and homophobic violence from public consciousness.

\section{Rural Men, Farming and the Internalisation of Violence}

Our study locations were selected because they exhibited indicators of violence. At the time of our fieldwork, many farming families throughout Australia were receiving forms of financial support in recognition of the severity and longevity of the prevailing drought and its economic impact on farm viability. This section focuses on rural men in our study locations who were farmers. This included farm owner / operators (more than half - 56\% - of Australia's farmers were self-employed owner / operators at the time of the 2011 Census (ABS, 2012), farm managers (who represented $17 \%$ of those in Australia identifying as farmers), farm workers, and some who wished to be full-time farmers but found it necessary to supplement income with off-farm employment.

The drought collided with a range of other pressures such as widespread population decline in the agricultural sector, business and farm losses, increasing agricultural automation and globalisation of production, the imperative to move to more sustainable farming practices, the rise of women's off-farm work, and challenges to the patrilineal inheritance of farming land (Lawrence, 1987; Pritchard \& McManus, 2000). These transformative changes have been linked to increasing crime, family violence and suicide in rural communities (Barclay, Foskey \& Reeve, 2007, p. 2; Hogg \& Carrington, 2006). At the same time, the farming population has been ageing (ABS, 2012; Stehlik, 2009), a factor that might be contributing to higher rates of injury experienced by rural men. In this section, we summarise the major themes to emerge from our interviews with and about male farmers and apparent propensities to internalise violence.

\section{Farming Men, Identity and Continuity}

For many Australian men (as in other countries as well), what they do - their skill or profession - is crucial to defining who they are, and their positioning in the field of masculinity (Carrington \& Scott, 2008; Cole, 2009). Rural culture centred on farming places a high value on productive activity and physicality in particular. Illness or retirement from work can strip farmers of their identity (Gergen \& Gergen, 2000) which can have negative implications for wellbeing through increasing the risk of depression and limiting life satisfaction and self-efficacy (Herzog \& 
Markus, 1999). One retired farmer we interviewed commented: 'If you've retired and don't have a job and nobody's listening; well, what is there?' If farmers' livelihoods are central to their identity, how do they prepare for retirement? Available statistics indicate that, increasingly, many do not (see, for example, Barclay et al., 2007; Foskey, 2005). In fact, we were told by one retired farmer: 'You can't plan for doing nothing'.

The issue of succession plaguing many farming families can lead to distressing and negative economic, social and health impacts, including violence. Decisions about retirement as well as property succession and inheritance are inexorably interrelated for farming families even though the issues are conceptually distinct. This is because the property is not only a place of business: it is also the family home and the hub of a way of life. There is often strong place attachment as well (Nalson \& Craig, 1987). To retire can also mean forced movement away from extended family members and a community of long standing. Greater degrees of complexity are now being experienced than in previous generations due to a variety of factors and conflicting interests, including declining profit margins and reduced cash flows, challenges to traditional norms such as primogeniture and the possibility of loss of all or part of the family farm through divorce settlements (McIntosh et al., 2009). Additionally, younger members of farming dynasties are showing less interest in continuing involvement (Barclay et al., 2007).

\section{Farm Loss, Loss of Status and Personal Failure}

In Australian agriculture and the rural social order more widely, the masculine has been regarded as the norm (Alston, 2000). Farmers, especially, feared failure through non-continuation of patriarchal farming 'dynasties' as illustrated by a rural financial counsellor with extensive experience:

Look, I've been to mediations and things that have brought men to tears, the fact that they could even go close to losing the land or part of it. It's sort of, it's not just the land; it's the generations that went before them.

Emotions linked with loss (through forced sale) of the family farm could be intensified when a younger generation had aspirations to farm. The thought of losing not only the farm but also in having no further use for skills and ways to earn income was also a source of anxiety. Another rural financial counsellor said:

Farmers classically say to me: 'I know that I probably should sell but what else would I do?' They have an amazing number of skills but they're a farmer.

One senior industry spokesman with intimate knowledge and experience of farmers facing forced foreclosure summarised their stressful predicaments:

They keep going ... they don't recognize that D-day's up until you're in a negotiation with the bank and the bank says: You're finished mate ... They don't really get over it ... When you're a farmer, your life is your farm, so when you lose it ... 
Rural Maculinities and the Internalisation of Violence in Agricultural Communities -

Carrington, McIntosh, Hogg \& Scott

Inability to achieve and meet expectations due to a range of factors negatively impact upon self-esteem. Ongoing drought conditions exacerbated situations to the extent that some male farmers come to regard themselves as failures, as victims of circumstances outside their control. Additionally, in smaller communities, men can be stigmatized if their farming enterprise collapses, with potentially fatal consequences as this comment illustrated:

And me brother-in-law, he was on the dairy farm for 30 years - and you know

how hard that is - and he had to start putting his cattle down and he tried to shoot himself and luckily he only [reflective pause]. And he saw himself as a failure.

The loss of identity and farming failure were often aggravated by changing dynamics within agriculture. Adapting to change, although essential, can be especially difficult during extreme events, as this recollection of a conversation with an older farmer illustrates:

A classic one day was said to me: 'I used to work harder when I needed more money and everything would be okay. Now I work harder and I go broke quicker.' That's where we're at.

Owning a rural property in Australia (as in most other agrarian economies) is traditionally a source of status and prestige (Hannan \& Commins, 1992). Thus some farmers were having problems with self-esteem not only due to the failure of their farming enterprises, but also because of their loss of standing within the wider community.

Successful men of the Australian 'squattocracy, ${ }^{5}$ and their family members have traditionally been associated with social, political and economic supremacy (Connell, 1995; Miller, 2008). Crucially, traditional farmers may not be well equipped with strategies to cope with change (Peter, Bell, Jamagin \& Bauer, 2000). Coldwell (2007) suggested that structural support networks need to be nurtured so that farmers with more dialogic conceptions of their masculinities can support others. In turn, farmers inclined towards monologic masculinities might be encouraged to reflect and develop more options for performing their farming identities. In this way emerging rural masculinities might become sources of empowerment with others rather than sources of power over others (Campbell, Bell \& Finney, 2006).

\section{Off Farm Work: Challenging Gender Identity Constructs}

The rural gender order is undergoing transformation with the rise of women in farming, the growth of women's off-farm employment, the erosion of patrilineal farming empires, the globalisation of agriculture, and technological changes to farming methods, all of which reduce the reliance on physicality and brute strength associated with rural men (Alston, 2000; Coldwell 2007; Hogg \& Carrington 2006; Lockie \& Bourke, 2001). Traditional gender constructions of farmers tend to accompany conservative and conventional approaches to farming and farm management (Foskey, 2005), and appear to be at odds with the demands of a future regime of adaptable and sustainable farming practices.

During our fieldwork, we were often told, one way or another, that primary producers are essentially optimists; if they weren't, they wouldn't be farmers. While optimism might largely be 
viewed as a positive attribute, when it becomes difficult to muster, negative consequences for wellbeing can flow. One prominent federal government advisor and farmer told us:

If you take away that optimism, well, you've got depression and that's probably one of the biggest problems that's occurring.

While many farmers do adapt to changing circumstances, clearly others struggle. Older male farmers, we were told, were particularly more likely to experience difficulties, believing they were too old to change and thus setting themselves up for failure, exacerbating increased levels of stress, depression and illness.

The partners of struggling farmers sometimes bore the brunt of both the mental and physical anguish being experienced by their partners. Our informants stressed that some farmers they knew felt like failures if their wives worked off-farm to become income providers. With women no longer as reliant on their menfolk for their livelihoods, these men feared what might happen if their wives' new experiences left them with less or no desire to stay on the farm. A processing plant manager told us that:

Some men struggle with that ... the men can't cope with the loss and that they

don't have that control over the women any more.

Thus the traditional role of the male breadwinner is challenged by the growth of women's off farm work. Nevertheless, off-farm work by women has become a family farm survival strategy (Kelly \& Shortall, 2002). With their wives or partners working away, farmers left behind usually have heavier workloads. This translates as reduced opportunities for time off from work to recuperate. Moreover, working partners and other family members can be absent for days at a time and relationships can become strained by distance. Lack of coping abilities sometimes manifest as violence against family members and domestic violence in particular.

\section{Self-reliance, Loneliness and Isolation}

Our respondents vouched for the essential accuracy of the classic portrayal of Australian farmers as exceptionally proud, stoic, self-reliant men of fortitude who saw asking for help a sign of weakness. This resoluteness to self-reliance means that troubling issues tend to remain internalized. Self-reliance can lead to long working hours, enhancing the risk of injury. Many farmers, we were told, would work long hours off- as well as on-farm to finance the purchase of their properties or essential equipment. The shame of asking for assistance is potentially heightened due to lack of anonymity, making public exposure of financial difficulties or other personal problems likely. Admitting to needing help was also regarded as a form of failure:

It's important to be seen as a farmer who knows his stuff, whether they do or not.

And I think in a lot of respects they're probably not being honest with themselves. I don't know what that does to their own wellbeing and self-worth.

We were repeatedly told that alcohol was used as a coping mechanism. One young farmer with mounting debts described how he used alcohol to aid sleep: 
Rural Maculinities and the Internalisation of Violence in Agricultural Communities Carrington, McIntosh, Hogg \& Scott

When I took on more cattle and bought the property next door and all the rest, you know, I couldn't sleep for three months sort of thing. And I figured the only way I could sleep was by drinking more alcohol which I hardly ever did at the time ... It took me probably two months to realise that if I did drink a reasonable amount of alcohol at night, I could sleep at least.

With no separation between workplace and home, farmers usually cannot escape elsewhere at the end of a working day. Attempts have been made to address farmers' levels of wellbeing through social interaction but this has become increasingly more difficult within rural communities for a number of reasons. Firstly, whereas professional advisers can assist with a range of management issues, this does not alleviate the workload. Secondly, women's off-farm work restricts their contributions on-farm and leaves their male partners in more isolated work environments. Thirdly, many core traditional activities that used to provide regular recreational outlets for families have ceased to exist. Consequently, opportunities to socialize are reduced and their life-world shrinks and becomes more internalised. Many farmers become enmeshed in their work situation to the virtual exclusion of all else and the detriment of their health. The effects of constrained opportunities for rest and recreation away from stressful workplaces were noted by this community leader:

Social problems were certainly being exacerbated by the fact that the families were restricted to the farm, couldn't get out for a release from the circumstances that they were being confronted with and therefore everything was just compounding and piling up on them ... the mental side of dealing with their problems was just as bad as the financial.

People respond to isolation in different ways under differing conditions. For those who live and work on farms, isolation is not necessarily a matter of choice. Whereas partners of farmers often have involvement in activities outside the family, such as through community volunteering, organisations such as the Country Women's Association, or involvement in their children's activities as well as off-farm work, farming men often have minimal exposure to social networks as they are still very much gendered in rural settings. Consequently, the nature of farm work has traditionally promoted isolation. Furthermore, the geographic remoteness of many rural properties makes it easier for men to remove themselves from interaction with others. Many respondents linked self-harm and suicide to these heightened levels of rural isolation and loneliness.

Farm injuries are exacerbated by long hours, increased periods of isolation and lack of affordability or willingness to source help for tasks. One respondent, a farmer who also coordinated wellbeing programs in farming communities, stated:

The biggest thing that [negatively] promotes mental health issues is lack of communication, meaning that farmers traditionally are more isolated, have to do things that they shouldn't do necessarily by themselves, by themselves; therefore take more risks.

Some respondents were aware that farmers tend to isolate themselves if they were known to have depression, had symptoms of bipolar disorder or perhaps had experienced a relationship 
breakdown. Often 'strange behaviour' was regarded more as a personality trait than an illness and serious talk among men about associated problems generally did not happen. Thus we were told:

People tend to tolerate them; sort of watch him, 'he's a bit crazy but he's alright' sort of thing... just tends to be brushed off.

\section{Loss and Illness Compounded}

We previously highlighted that farmers who are forced to sell their properties often also lose their home, their sense of identity, and their self-esteem. According to counsellors, mediators, rural program coordinators and service providers that we interviewed, these types of occurrences were regularly accompanied by health issues. Farmers with depression or other perhaps untreated illnesses often demonstrated that they were not able to appropriately manage farm operations. The effects of chronic or toxic stress need to be considered as a major challenge to individual's physical and psychological health with both aspects at risk (McEwen, 1998). Moreover, potential consequences of mental illness and toxic stress include violent behaviour and self harm.

Men - especially rural men - are generally more reluctant to seek medical treatment than women (AIHW, 2010; Courtenay, 2006), as illustrated by this conversation with a farmer client which was recollected by a counsellor we interviewed:

I said: 'I've found this counsellor who would go on farm to you' and: 'Would that be better?' and: 'Have you used that referral?' And he said: 'Oh I've been intending to but on the bad days I don't want to talk to anybody and on the good days I don't need to so I haven't rung them' ... He wasn't going to make that call.

We were frequently told that most men from our study locations would not seek medical treatment when a health condition had become manifestly apparent. Many respondents that we interviewed who worked in agriculture were not even aware of services or organisations within their area that could benefit men. There are undoubtedly numerous reasons for men's reluctance to seek assistance or present with an illness. Where farmers worked constantly throughout daylight hours and perhaps lived some distance from services, there are recognised difficulties in making and / or keeping appointments, particularly in rural towns where services are stretched or limited with lengthy waiting times

Not coping and feeling threatened exacerbate already fragile personal and family relationships, leading to more problems, suspicions, and tensions within families. Sometimes complex arrays of emotions and situations could initiate vicious and self-sustaining cycles of decline, erupting as violence towards self or even against others. Many of our respondents who were professional advisers had witnessed or experienced these episodes of violence with their clients.

\section{Self-harm, Including Suicide}

Our analysis of interviews conducted in our agricultural study locations have served to illustrate that farmers' susceptibilities to becoming victims and perpetrators of forms of violent 


\section{Rural Maculinities and the Internalisation of Violence in Agricultural Communities - Carrington, McIntosh, Hogg \& Scott}

harm can be influenced through a range of circumstances. Powerful negative emotions manifest as physical and / or psychological neglect, self-abuse, even physically violent self-harm. Some of our respondents recalled hearing 'victim statements' from people they knew within their farming communities. For instance, a coordinator of wellbeing programs for farmers related an experience to us where:

I got there in the morning and I said: 'How are you?' [He said] 'Like shit! It's just too hard. You know, everything I do, it doesn't matter what I do' - and I think he's a pretty good farmer - 'doesn't work. Don't get paid for my product; what am I doing? There's so much government regulation coming in'; and all the rest of it. They're really feeling like victims and that's creating mental health issues.

Bankruptcy, unemployment and financial difficulties can lead to depression and hopelessness, all known risk factors for suicide and for Australian farmers facing continuing and extremely adverse conditions (AIHW, 2010). Elevated rates of suicide among farmers have been recognised (Judd et al., 2006) and featured in our study locations. Economic and financial hardships have been identified as possible reasons for regional differences in suicide rates (AIHW, 2010; DHA, 2008). They may also lead to other problems such as relationship conflict or breakdown, gambling or substance abuse. Isolation or remoteness and lack of close social networks may also be contributing factors. One publican summarised it for us this way:

And you put it all together ... and it all just boils over ... you get to a stage of saying: What am I doing ... on this farm out here ... what am I doing this for?

I'm doing it for nothing. And it gets you down.

Factors presented by participants in our research project as leading to self-harm included, on the one hand, isolation, aloneness, stress, perceived failure, low self-esteem, relationship breakdown, alcohol or drug use, poor coping skills, harmful role and peer models, and depression. On the other hand, external factors such as extreme seasonal conditions, market fluctuations, financial problems and family rifts were sometimes part of the mix.

Mostly our informants were surprised and shocked when they learned that a family member, friend, neighbour or acquaintance had committed suicide because they had no forewarning. Overwhelmingly the futility of the suicides was cause for anguish. For example, we recorded the following responses:

They feel they've got nothing else to go to; when things start falling apart, they don't know what to do. (President of a sporting club)

He was a married man, fairly, well, you could say affluent, he owned a lot of property, owned a lot of cattle and, ah, we were actually, he was coming to the races the day he shot himself. The horses we raced together won the day he shot himself. It blew me away, you know. (Publican of a small rural town) 
No one really saw them coming. I don't know if you ever really know what's going on with people but it just seemed to be that they couldn't cope with life or they couldn't cope with failure. (Processing plant manager)

The risk of suicide was regarded as a serious problem among male farmers in our study locations. Australian research by Judd et al. (2006) has found that the rising rate of suicide among farmers cannot be simply explained by an elevated rate of mental health problems. We believe rising rates of suicide among rural men in agricultural communities are emblematic of the decline of pub(lic) masculinity and the internalisation of violence.

\section{Conclusion}

In summary, our case studies presented in this article illustrate how the social characteristics of masculinities associated with farming and mining communities have shaped identifiably different patterns of cultural conflict and violence. Violence turned inward and violence turned outward emerged as the two key themes. In the mining communities we studied, the rise in pub(lic) masculinity has had manifold consequences for the patterning of frontier cultural conflict and visible forms of brawling and alcohol-fuelled violent behaviour. Conversely, in the rural communities we studied the decline in such pub(lic) masculinities has exacerbated levels of isolation for rural men, especially farmers, and in turn influenced rates self harm and violence much of which remains hidden from public view. Rising suicide rates in agricultural communities are arguably symptomatic of this internationalisation of violence. Many Australian farming communities are facing multiple challenges to their way of life. Our study supports earlier research (Courtney, 2006) which suggests that rural men whose masculine identities thrive on self-reliance, stoicism and fortitude these may actually enhance their propensity to both commit and internalise violence.

The distinctively different patterns of men's experiences of violence in agricultural compared with mining communities illustrates the diversity of different kinds of rurality. Clearly, rurality is more than a residual category for all that is non-urban but is, rather, illustrative of the ways localised forms of social structure, social norms and related cultural patterns define people's experience with crime as both offenders and victims. Our case studies are also exemplary of what C. Wright Mills famously conceptualised in The Sociological Imagination (1959) as the way private troubles are bound up with wider historical dynamics and social norms that impact on ordinary lives. Our case studies illustrate how larger social forces, such as the post-industrial forces linked to the globalisation of the resources sector and the technologicalisation of agriculture, impact on patterns of violence at a local level. This further demonstrates the necessity for and strength of qualitative case studies that contextualise explicit dimensions and patterns of rural crime in divergent contexts. ${ }^{6}$ Our research, upon which this article is based, represents a beginning in a rich research field where there is clearly much more to do on the divergent contexts of violence in rural communities. 
Rural Maculinities and the Internalisation of Violence in Agricultural Communities Carrington, McIntosh, Hogg \& Scott

\section{Endnotes}

${ }^{1}$ We acknowledge the support of ARC Discovery Project 2008-2011 DP0878476.

${ }^{2}$ The Australian Bureau of Statistics uses the 'Remoteness' framework to enable comparisons between 'city', 'country' and 'outback' Australia. This structure distinguishes between Major Cities at one end of the scale and, at the other, Remote and Very Remote areas. In between are Inner Regional and Outer Regional areas. The defining difference is level of remoteness, in terms of distance and access to goods and services.

${ }^{3}$ One of the best Australian examples of multi-dimensional measures of community disadvantage is the method used by Vinson $(1999,2004,2007)$, which was produced for Jesuit Social Services in Australia. Vinson measured five main domains of disadvantage social distress, health, community safety, economic, and education - and accessed data from a large range of sources, including the ABS, Centrelink, the Health Insurance Commission, as well as state and territory authorities. Vinson found that disadvantage is highly concentrated in a small number of areas; in 2007, for example, just $1.7 \%$ of Australian postcodes and communities account for over seven times their share of the main factors that entrench disadvantage, such as low income, limited access to computers and the Internet, early school leaving, prison admissions and confirmed child maltreatment .

${ }^{4} \mathrm{FIFO} / \mathrm{DIDO}$ is the acronym used for 'fly-in, fly-out, drive-in, drive-out' workers (also called 'non-resident workers' and 'long distance commuters') who travel large distances from their place of usual residence to work 12-hour shifts within extended rosters (long work cycles usually followed by shorter leave cycles) in regional and remote locations. Most are employed by or linked with the resources sector. Particularly during Australia's mining 'boom' of recent years, this form of workforce practice has been embraced for the construction, operation and maintenance of mining, processing, transportation and associated projects (including work camp management, catering and security) and has also been adopted for other types of workers demanded by the industry such as sex-workers. FIFO / DIDO is practiced not only in remote locations but increasingly in regional areas which have established communities and a long history of dependence on agriculture.

${ }^{5}$ Squattocracy (from the word 'squatter') refers to the long-established and (historically) wealthy owners of large agricultural holdings (farms or ranches) in Australia. Traditionally and anecdotally, some multi-generational members of the squattocracy are accustomed to having influence, especially in decision-making processes, and high social standing in rural communities.

${ }^{6} \mathrm{We}$ are grateful to the insights of the reviewer for helping us rewrite our conclusion. 


\section{References}

ABS (Australian Bureau of Statistics). (2008). 2006 Census of population and housing. Canberra: ABS.

ABS (Australian Bureau of Statistics). (2011). 3218.0 Regional population Growth, Australia, 2009-10. Canberra: ABS

ABS (Australian Bureau of Statistics). (2012). Australian farming and farmers, 4102.0 Australian social trends, December 2012. Canberra: ABS.

Alston, M. (1997). Violence against women in a rural context. Australian Social Work 50, 15-22.

Alston, M. (2000). Breaking through the grass ceiling: Women, power and leadership in agricultural organisations. The Netherlands: Harwood Academic Publishers.

Australian Institute of Health and Welfare (AIHW) 2010. A snapshot of men's health in regional and remote Australia. Canberra: AIHW, Rural Health Series No. 11, Cat No. PHE 120.

Barclay, E., Donnermeyer, J.F., Scott, J., \& Hogg. R. (Eds). (2007). Crime in rural Australia. Sydney: The Federation Press.

Barclay, E., Foskey, R., \& Reeve, I. (2007). Farm succession andiInheritance- comparing Australian and international trends. Canberra: Rural Industries Research and Development Corporation, Publication No. 07/066.

Baum, S., O’Connor, K. \& Stimson, R. (2005). Fault lines exposed. Melbourne: Monash University ePress.

Baum, S., Stimson, R., O'Connor, K., Mullins, P., \& Davis, R. (1999). Community opportunity and vulnerability in Australia's cities and towns: Characteristics, patterns and implications. Australian Housing and Urban Research Institute, Brisbane: University of Queensland Press.

Campbell, H. (2000). The glass phallus: Pub(lic) masculinity and drinking in rural New Zealand. Rural Sociology, 65, 562-581.

Campbell, H. (2006). Real men, real locals and real workers: Realizing masculinity in small town New Zealand. In H. Campbell, M.M. Bell \& M Finney (Eds.), Country boys: Masculinity and rural life (pp. 87-104). Pennsylvania: Pennsylvania State University Press.

Campbell, H., Bell, M.M., \& Finney, M. (2006). Masculinity and rural life: An introduction'. In H. Campbell, M.M. Bell \& M Finney (Eds.), Country boys: Masculinity and rural life (pp. 122). The Pennsylvania State University Press: Pennsylvania.

Carrington, K., \& Hogg. R. (2011). Benefits and burdens of the mining boom for rural communities. Human Rights Defender. Sydney: University of New South Wales Law Faculty.

Carrington, K., \& Scott, J. (2008). Masculinity, rurality and violence. British Journal of Criminology, 48, 641-66. 
Rural Maculinities and the Internalisation of Violence in Agricultural Communities Carrington, McIntosh, Hogg \& Scott

Carrington, K., Hogg, R., \& McIntosh, A. (2011). The resource boom's underbelly: The criminological impact of mining development. Australian and New Zealand Journal of Criminology, 44, 335-54.

Carrington, K., McIntosh, A., \& Scott, J. (2010). Globalization, frontier masculinities and violence: Booze, blokes and brawls. British Journal of Criminology, 50, 393-413.

Coldwell, I. (2007). Masculinities, crime and criminology: More than just shit kickers, we're switched-on farmers wanting to balance lifestyle, sustainability and coin. Journal of Sociology, 43, 87-104.

Cole, T. (2009). Negotiating the field of masculinity: The production and reproduction of multiple dominant masculinities. Men and Masculinities, 12, 30-44.

Connell, R.W. 1995. Masculinities. Sydney: Allen and Unwin.

Courtenay, W.H. (2006). Rural men's health: Situating risk in the negotiation of masculinity. In H. Campbell, M.M. Bell \& M Finney (Eds.), Country boys: Masculinity and rural life (pp. 139158). Pennsylvania: Pennsylvania State University Press.

DeKeseredy, W.S. (2011). Violence against women. Toronto: University of Toronto Press.

DeKeseredy, W.S., \& Schwartz, M.D. (2009). Dangerous exits: Escaping abusive relationships in rural America. Rutgers University Press:

Department of Health and Ageing (DHA) (2008). Living is for everyone, fact sheet 18: Suicide in rural and remote communities. DHA: Canberra.

Foskey, R. (2005). Older farmers and retirement. RIRDC Report No. 05/006. Canberra: Rural Industries Research and Development Corporation.

Gergen, K., \& Gergen, M. (2000). The new aging: Self construction and social values. In K.W. Schaie (Ed.), Social Structures and Aging (pp. 281-306). New York: Springer.

Hannan, D., \& Commins, P. (1992). The significance of small-scale landholders in Ireland's socioeconomic transformation. In J. Goldthorpe and C. Whalen (Eds.), The development of industrial society in Ireland (pp. 79-104). Oxford: Oxford University Press.

Herzog, A., \& Marcus, H. (1999). The self concept in life span and ageing research. In V.L. Bengston \& K.W. Schaie (Eds.), Handbook of theories of ageing (pp. 227-252). New York: Springer Publishing Company.

Hogg, R., \& Carrington, K. (2006). Policing the rural crisis. Sydney: The Federation Press. Infrastructure (Department of Infrastructure, Transport, Regional Development and Local Government). (2008). Road deaths Australia: 2007 statistical summary. Road safety report No. 1. Infrastructure: Canberra.

Judd, F., Jackson, H., Fraser, C., Murray, G., Robins, G., \& Komiti, A. (2006). Understanding suicide in Australian farmers. Journal of Social Psychiatry and Psychiatric Epidemiology, 41, $1-10$.

Kelly, R., \& Shortall, S. (2002). Farmers' wives: Women who are off-farm breadwinners and the implications for on-farm gender relations. Journal of Sociology, 38, 327-343. 
Lawrence, G. (1987). Capitalism and the countryside: The rural crisis in Australia. Sydney: Pluto Press.

Liepins, R. (2000). Making men: The construction and representation of agriculture-based masculinities in Australia and New Zealand. Rural Sociology, 65, 605-620.

Lockie, S., \& Bourke, L. (Eds). (2001). Rurality bites: The social and environmental transformation of rural Australia. Sydney: Pluto Press.

Macklin, M. (1995). Breaching the idyll, ideology, intimacy and social service provision in a rural community. In P. Share (Ed.), Communication and culture in rural areas. Charles Sturt University, Centre for Rural Social Research

McEwen, B.S. (1998). Stress, adaptation, and disease: Allostasis and allostatic load. Annals of the New York Academy of Sciences, 840, 33-44.

McIntosh, A., Carrington, K., \& Scott, J. (2009). Exit strategies for ageing male farmers in rural Australia (conference paper). Balancing choices and effects in a dynamic world. Cairns Institute of Australian Geographers 2009 Conference, 28 September - 1 October.

Miles, M., \& Huberman, A. (1994). Qualitative data analysis: An expanded sourcebook (2nd ed.). Thousand Oaks, California: Sage.

Miller, P. (2008). Antipodean Patrimonialism? Conference abstracts, Lineages of patrimonial politics, then and now. The Centre for Comparative Research, May 9-10 New Haven: Yale University.

Mills, C.W. (1959). The sociological imagination. New York: Oxford University Press.

Nalson, J.S., \& Craig, R.A. (1987). Rural Australia. In S. Encel (Ed.), Selected readings in Australian society (pp. 311-343). Melbourne: Longman and Cheshire.

Owen, S. (2012). Integrated response policy to domestic violence in NSW: A critical analysis. (doctoral dissertation). Queensland University of Teachnology, School of Justice.

Peter, G., Bell, M., Jamagin, S., \& Bauer, D. (2000). Coming back across the fence: Masculinity and the transition to sustainable agriculture. Rural Sociology, 65, 215-234.

Pritchard, B., \& McManus, P. (Eds). (2000). Land of discontent: The dynamics of change in rural and regional Australia. Sydney: UNSW Press.

Scott, J., Carrington, K., \& McIntosh, A. (2012) Established-outsider relations and fear of crime in mining towns. Sociologica Ruralis, 52, 147-169.

Spradley, J. (1979). The ethnographic interview. New York, Holt: Rinehart and Winston.

Stehlik, D. (2009). Intergenerational transitions in rural Western Australia: an issue for sustainability? In F. Merlan (Ed.), Tracking rural change: Community, policy and technology in Australia, New Zealand and Europe (pp. 135-150). Canberra: Australian National University.

Vinson, T. (1999). Unequal in life: The distribution of social disadvantage in Victoria and New South Wales. Richmond, Victoria: The Ignatius Centre for Social Policy and Research. 
Rural Maculinities and the Internalisation of Violence in Agricultural Communities Carrington, McIntosh, Hogg \& Scott

Vinson, T. (2004). Community adversity and resilience: The distribution of social disadvantage in Victoria and New South Wales and the mediating role of social cohesion. Richmond Victoria: Jesuit Social Services.

Vinson, T. (2007). Dropping off the edge: The distribution of disadvantage in Australia. Richmond Victoria and Curtin, ACT: Jesuit Social Services and Catholic Social Services Australia.

Weisheit, R., Falcone, D., \& Wells, E. (1996). Crime and policing in rural and small town America. Prospect Heights, Illinois: Waveland Press. 